Research Article

\title{
Improving Mathematical Reasoning and Mathematics Attitude of Disadvantaged Children in Rural Regions
}

\author{
Emrullah ERDEM *1 (D), Tahsin FIRAT 2 (D) Ramazan GÜRBÜZ3 3 (D) \\ ${ }^{1}$ Adryaman University, Faculty of Education, Adryaman, Turkey, eerdem@outlook.com \\ ${ }^{2}$ Adryaman University, Faculty of Education, Adryaman, Turkey, tahsinfirat02@gmail.com \\ ${ }^{3}$ Adryaman University, Faculty of Education, Adryaman, Turkey, rgurbuz@outlook.com \\ *Corresponding Author: eerdem@outlook.com
}

\begin{tabular}{|c|c|}
\hline Article Info & Abstract \\
\hline $\begin{array}{l}\text { Received: } 3 \text { October } 2019 \\
\text { Accepted: } 25 \text { October } 2019\end{array}$ & $\begin{array}{l}\text { This study aims at examining the effects of an enriched learning } \\
\text { environment on improving Mathematical Reasoning (MR) and } \\
\text { Mathematics Attitude (MA) of disadvantaged children }(11 \text {-and } 12 \text {-year- } \\
\text { olds). The participants were } 5^{\text {th }} \text { graders }(\mathrm{N}=17) \text { and } 6^{\text {th }} \text { graders }(\mathrm{N}=18) \\
\text { who were studying in a rural school in a province of Turkey. The data } \\
\text { were obtained via Mathematical Reasoning Test (MRT), Mathematics } \\
\text { Attitude Scale (MAS), and groups argumentation. A Wilcoxon Signed }\end{array}$ \\
\hline $\begin{array}{l}\text { Keywords: Design of learning } \\
\text { environment, mathematical } \\
\text { reasoning, mathematics attitude, 5th } \\
\text { and 6th-graders, schools in rural } \\
\text { regions }\end{array}$ & $\begin{array}{l}\text { Rank test was used to reveal the pre/post-test differences. Statistical } \\
\text { comparisons of the MR and MA were also made by using the tests' } \\
\text { mean scores. There is evidence from the environment that the MR of } \\
\text { both groups was significantly developed but grade/age did not have a } \\
\text { significant effect on MR. The study found that the MA of both groups } \\
\text { improved after the intervention, but these improvements were not }\end{array}$ \\
\hline DOI: $10.18009 /$ jcer.628742 & $\begin{array}{l}\text { statistically significant. No significant effect was determined regarding } \\
\text { age on the improvement of MA. This research has shown that the MR }\end{array}$ \\
\hline Publication Language: English & $\begin{array}{l}\text { and MA of children of such disadvantaged rural regions can improve } \\
\text { when rich learning environments are designed. }\end{array}$ \\
\hline CrossMark CC & $\begin{array}{l}\text { To cite this article: Erdem, E., Firat, T., \& Gürbüz, R. (2019). } \\
\text { Improving mathematical reasoning and mathematics attitude of } \\
\text { disadvantaged children in rural regions. Journal of Computer and } \\
\text { Education Research, } 7 \text { (14), 673-697. DOI: } 10.18009 / \text { jcer.628742 }\end{array}$ \\
\hline
\end{tabular}

\section{Introduction}

When mathematical problems are examined, it can be seen that they require different levels of reasoning. For example, which of the following tasks is more challenging: (i) "What are the two numbers with a total of 7 ?", (ii) "If $\Delta+3=7$, what is $\Delta$ ?", or (iii) "If $\Delta+(-3)=7$, what is $\Delta$ ?" If generating the solution to such tasks requires more mathematical effort, then those tasks are perceived as difficult and thus children have anxiety about them. Why do they have difficulty with these kinds of tasks or problems? The reason is that such problems require more mathematical reasoning that students have not developed, or are not prepared to use. Previous studies demonstrate that such a difficulty in mathematics stems from superficial reasoning and rote learning strategies (Lithner, 2000b; 2003; 2017). For example, in 
the second task (ii), the answer to the question "What number makes 7 by adding 3 to it?" is 4. In the third task (iii), as an individual thinks "What number makes 7 by adding ( -3$)$ to it?" they might wonder whether or not to add a number "-3" at first. With a little reasoning, one can determine that the solution is 10 . The first problem, (i), is the problem that requires the most mathematical reasoning. The individual must first think about which two numbers give a total of $7(4+3,5+2,6+1$, etc.), before deciding what to do and which strategy to follow. Moreover, with additional reasoning, s/he may offer more complex alternatives in the form of $9+(-2), 8+(-1), 7+0$, etc. or additional different forms. The first task is more challenging than others and therefore requires more mathematical reasoning.

Lithner (2000b) defines reasoning in mathematics as "the line of thought, the way of thinking, adopted to produce assertions and reach conclusions" (p. 166). Mathematical Reasoning (MR) is a skill that involves higher-order thinking (Erdem, 2015). Jeannotte and Kieran (2017) have explained that MR includes the following processes: a) generalizing, $b$ ) conjecturing, c) identifying a pattern, d) comparing, e) classifying, f) validating, g) justifying, $h$ ) proving, and i) exemplifying. In order to solve a mathematical problem, one has to decide on possible consequences and choose between alternative results (Holyoak \& Morrison, 2005). This decision-making process usually requires reasoning-or, in other words, high-level thinking. These multiple thinking processes clearly show why MR is a critical skill for students to develop.

\section{Improving Mathematical Reasoning}

It is important to encourage the development of $\mathrm{MR}$, because it is understood to improve critical thinking in learning environments. The focus on students' reasoning in such

environments should be inquiry-based (Hunter, 2008). The greatest obstacle to improving children's MR is the lack of classes suitable for developing mathematical reasoning (Brodie, 2010) but it is challenging to design mathematics classes to improve MR. If supportive classes are provided, all students can make inferences, refute these inferences, and develop appropriate MR (Yackel \& Hanna, 2003).

Previous literature yields many studies that demonstrate the necessity of designing appropriate learning environments to improve MR (e.g., Erdem, 2015; Hunter, 2014; McCrone, 2005; Norqvist, 2018; Staples \& Truxaw, 2012). Activities in learning environments can only reach their goal if they are based on students' existing MR and mathematical accuracy (Lithner, 2000a). In environments that will serve this purpose, students should be 
able to discover new ideas, develop assumptions, make connections, and justify their thoughts (Hunter, 2012). Studies have suggested that allowing students to explain their thoughts helps develop MR (Erdem, 2015; Pape, Bell \& Yetkin, 2003). In this context, it is important and necessary to teach and encourage the use of judgments when students reason, such as "If ... so...", "because ...", "I realized that ...", "I decided that ...", "I did not understand because...", "We can also look at this point...", "I wonder what else could be..." etc. Using such patterns is an indicator of MR (Mason, 2001) and contributes to development of MR (Clarkson, 2004). Norqvist (2018) emphasized the contribution of education to MR through teaching students how to explain rules rather than using those rules directly when learning mathematics.

On the other hand, an environment in which students interact with each other and share their mathematical ideas is the ideal incubator for the development of $M R$ (Yankelewitz, Mueller \& Maher, 2010). MR develops through social interactions, games, and constructive discussions between individuals (Schliemann \& Carraher, 2002). Vygotsky (1978) suggests that a child's reasoning develops in environments where s/he is living with her/his peers and entering social interaction. Good encouragement and relevant feedback from teachers is also necessary to improve MR (Bragg et al., 2016). Moreover, previous studies have revealed that MR developed effectively in classes that combined different teaching methods (Erdem, 2015): for example, computer-aided instruction (Kramarski \& Zeichner, 2001), teaching with educational games (Olson, 2007), and enabling students to learn by discussing (Kuhn, Shaw \& Felton, 1997; Yackel, Cobb \& Wood, 1999). Researchers also found that making students take note of the strategies they used and allowing them to discuss these strategies with their teachers and friends while solving the problems made a significant contribution to MR (Ellis, Özgür \& Reiten, 2018; Pape et al., 2003).

\section{Mathematics Attitude}

Attitudes are not the behaviors, but the psychological variables behind the behaviors of people (Şengül \& Dereli, 2013). Students' attitudes towards mathematics (positive or negative) either make math learning easier or difficult. The difficulty of mathematics is due to the negative attitude and fear developed against it as well as its structure (Erdem \& Soylu, 2019). There are many reasons for such negative attitudes towards mathematics. For example, (1) the successful or intelligent characterization of students is largely related to mathematics, (2) the mathematics taught after the first grade of primary education become 
increasingly abstracted from daily life, (3) intense curriculum programs and (4) some negative teacher behaviors are some of them (Uğurel \& Moralı, 2006). The relationship between attitude and behavior in mathematics learning is explained in two cycles as positive attitude and negative attitude cycle (Nisbet, 2006): Students with positive attitudes towards mathematics like mathematics and try to do better, so they exhibit positive behavior and enjoy success. This success ensures that their attitude improves and the cycle continues (Figure 1-a). Conversely, in the negative attitude cycle, the student who does not like mathematics tries less and experiences failure; thus, this leads to more negative attitudes (Figure 1-b).

\section{Students likes mathematics}

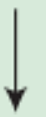

Student has intention of doing well<smiles>[3H]C</smiles>

Student works hard

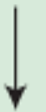

Student experiences success and enjoyment

a. Positive attitude cycle
Students dislikes mathematics

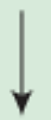

Student has little intention of trying

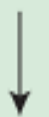

Student does little work

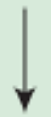

Student experiences failure and no enjoyment

b. Negative attitude cycle

Figure 1. Positive and negative attitude cycles (Nisbet, 2006)

Mathematics Performance of Children in Rural Regions

MR skill is important and necessary for disadvantaged rural children who benefit from fewer opportunities when compared with their urban peers. The Socio-Economic Status (SES) of rural families is lower than those of urban and suburban families, and this is the case in this study. Children from families with low SES are more likely to suffer from mathematics failure (Jimerson, Egeland \& Teo, 1999; Starkey, Klein \& Wakeley, 2004). The literature suggests multiple reasons for this phenomenon: (i) since early childhood, these children have grown up in an environment where mathematical concepts are used less frequently, thus their number sense (which is essential for mathematics) is not well developed (Gersten \& Chard, 1999). In their study, Judge \& Watson (2011) found that students from lower SES homes who experienced mathematics failure in preschool continued these failures at the end of the 5th grade. (ii) Families of children from low SES 
backgrounds may be inadequate in providing educational support (homework, follow-up, etc.) to their children (Fan \& Chen, 1999). The relationship between low SES and difficulties in learning mathematics continues across elementary, middle and high school due to the low support that these families give to their children (Starkey et al., 2004). Jimerson et al. (1999), in their longitudinal study, followed students who were at risk of failure from the first grade of primary school to 16 years old. They found out that environmental factors, the quality of the home environment, parental participation in the child's education, and SES were closely related to the success of reading and mathematics in the first grade, and this trend continued through middle and high school. (iii) Low SES families in developing countries such as Turkey are mostly living in rural areas (Öğdül, 2010), often to migrate to other regions as seasonal agricultural workers with their children, and these children typically help their families in different jobs during the summer (off-school season) (Çiftçi, \& Cin, 2018). In research related to education in rural areas in Turkey, scholars have identified problems that pose barriers to success such as poor physical conditions in schools, insufficient educational materials, family and society not valuing education, transport problems, lack of teacher training, and teachers' negative attitudes (Çiftçi \& Cin, 2018). All of these disadvantages can cause children living in rural regions to fall behind their peers in mathematics learning and face failure. Due to the low mathematical performance of these disadvantaged children, it can be hypothesized that their MR needs to be developed further.

The Importance of the Study

The present study examined how the MR and Mathematics Attitudes (MA) of children studying in disadvantaged rural regions improved in a well-designed environment. An inability to integrate MR occurs due to the prejudice and negative attitude towards mathematics, as well because of the structure of the discipline of mathematics. The generaly negative attitude towards mathematics is illustrated through individual students' behavior, and it can be an obstacle to mathematics success when no preventative or interventionary measures are taken. In order to transform negative attitudes to positive ones, different activities and practices should be included in learning environments that will attract students' interests, encourage curiosity, enable them to work in cooperation, and allow them to find knowledge themselves (Erdem, 2015). In this study, age-appropriate and fun educational games, computer applications that enable the use of technology, concrete materials that allow students to understand their own learning, constructive discussions 
between cooperative heterogeneous groups, and open-ended problems that stimulate highlevel thinking were employed. The aim of this study is to improve the MR and MA of 5th and 6th grade students living in disadvantaged rural regions through different and entertaining methods. In this way, the children not only felt more motivated to develop their MR and knowledge, but their parents and teachers were also more motivated to create appropriate environments for the children and help them make progress.

\section{Method}

\section{Research Design}

In this study, a pre-and post-test model was used to determine the effect of an intervention on the participants' MR and MA. The present study is also a cross-age study since this allows the researcher to compare the changes experienced by two different age groups.

\section{Subjects}

The present study was conducted with 5 th grade $(\mathrm{N}=17)$ and 6 th grade $(\mathrm{N}=18)$ students who are studying in a disadvantaged rural school in a province in Turkey. In the study, an intervention program was carried out by using different teaching methods in order to teach the subject of "fractions." The reason for choosing these two class levels is that the subject of fractions is first introduced in the 5th grade, but mainly covered in the 6th grade (MoNE, 2013). Most of the students (60\%) in this school, which is in a low SES area, are transported from the surrounding villages to the school by means of vehicles (minibusses) every day. The literacy rate of the fathers of the participants is $50 \%$ high school, $30 \%$ middle school, $10 \%$ primary school, and $10 \%$ illiterate, while mothers are $5 \%$ high school, $10 \%$ middle school, $65 \%$ primary school, $20 \%$ illiterate. The average per capita income for families with an average of 8 individuals varies between 500-2000 tl (100-400 dollars) per year. In addition, many students and their families travel to work in different provinces as seasonal workers. Since the school is in a rural region, teachers receive new appointments and thus are relocated every 2-3 years. All these factors make the students studying at this school disadvantaged, compared to their peers. Over the course of this study, students were motivated to receive support from the researcher who is expert on special education in order to help them with their special learning problems. The students participating in the study were placed in four heterogeneous groups (See Figure 1-e), making sure that each group 
represented a variety of different levels of mathematics achievement (determined through the students' mathematics grades). Because of this, students were able to learn more by discussing their mathematics work with their group members. In order to keep the identity of the participants secret, students were given codes such as Student A, Student B, Student C, etc.

\section{Data Collection}

The data of both groups (5th and 6th graders) were obtained from the answers given to 1) a Mathematical Reasoning Test (MRT), which was developed by using the literature (Erdem, 2011; 2015) and consisted of 22 open-ended problems about fractions and 2) the Mathematics Attitude Scale (MAS) (20 items) by Aşkar (1986) in the pre-test and post-test. Before the study implementation, the tasks in the MRT were evaluated by three mathematics education experts and three middle school mathematics teachers regarding of their suitability to the respective class levels, whether they were related to fractions, and whether they required mathematical reasoning. As the pilot study, the MRT with 24 tasks was applied to a total of 107 students, 52 of whom were in the 5th grade, and 55 of whom were in the 6th grade. As a result of the item analysis, two tasks were excluded from the test, with the item total correlation of both grades being below .20. The pilot study demonstrated that the students understood the questions on MRT, and thus pre-implementation measurements were taken. At the end of these analyses, the MRT was completed in its final form, consisting of 22 tasks. The Cronbach Alpha coefficient of the MRT was calculated as .791 for Grade 5 and .863 for Grade 6. The Cronbach Alpha coefficient for the MAS was determined to be .854 for the 5th Grade and .845 for the 6th Grade. A high score on the MAS indicates a positive attitude towards mathematics and a low score indicates negative attitudes. The lowest score that can be generated by the MAS is 5 and the highest score is 100 . Some additional data were obtained through the students' argumentation on the problems that required them to discuss the fractions in collaborative groups throughout the implementation process. Some quotations from these group argumentation sessions are reported in the Findings section of this article. 


\section{Data Analysis}

The data were analyzed using the Statistical Package for Social Sciences (SPSS 22) program. Since the number of both 5th grade and 6th grade students is fewer than 30 , nonparametric tests were used for data analysis. In addition, the Shapiro-Wilk test revealed that the data were not distributed normally at both grade levels $(p=.012$ for grade 5 and $p=.011$ for grade 6). The MRT and MAS were applied to all students as a pre-test before the implementation process and as a post-test at the end of the process. The change between the MRT and MAS scores of both grades of students was determined using the Wilcoxon Signed Rank test. In order to determine the effect of grade on MRT and MAS results, a MannWhitney $U$ test was used by calculating the pre-test/post-test differences of the groups. The rubric developed by Erdem (2011) was used to score the answers to the tasks in the MRT (See Table 1). According to this rubric, the scoring of each task varied between 0 and 5 points. Therefore, the minimum score which can be taken from the MRT consisting of 22 tasks is 0 and the maximum is 110 .

Table 1. The rubric scoring the tasks in MRT (Erdem, 2011)

\begin{tabular}{lcl}
\hline Levels & Score & Explanation \\
\hline Completely Correct & 5 & Statements that are accepted to be completely true \\
\hline Partly Correct-A & 4 & Missing statements according to complete true response \\
\hline Partly Correct-B & 3 & $\begin{array}{l}\text { Partly true statements that are fulfilled depending on the correct } \\
\text { reason }\end{array}$ \\
\hline Partly Correct-C & 2 & $\begin{array}{l}\text { Statements that are fulfilled by depending on a wrong cause or not } \\
\text { depending on any kind of reason and accepted to be partly correct }\end{array}$ \\
\hline Wrong & 1 & $\begin{array}{l}\text { Statements that are completely wrong or not completely related to the } \\
\text { question. }\end{array}$ \\
\hline Unanswered & 0 & $\begin{array}{l}\text { Statements where no explanation is given or the question itself was } \\
\text { given as a response }\end{array}$ \\
\hline
\end{tabular}

The mean scores of each student at the pre-test and post-test for MRT were calculated and the MR level at the pre-test and post-test was determined. The mean score/MR level of each student was calculated by dividing the total score obtained from the MRT by the number of tasks in the MRT (22 tasks). For example, a student with a total score of 83 from the MRT according to the scoring rubric in Table $1[83 / 22=3.77$ average score is between 3.00-3.99] (See Table 2), the MR level is considered as "High". 
Table 2. Mathematical Reasoning Levels

\begin{tabular}{ll}
\hline Level & Score Interval $(\bar{x})$ \\
\hline Quite Low & $0.00-0.99$ \\
Low & $1.00-1.99$ \\
Medium & $2.00-2.99$ \\
High & $3.00-3.99$ \\
Quite High & $4.00-5.00$ \\
\hline
\end{tabular}

How the Learning Environment was Designed

According to the pre-determined learning outcomes of the Turkish Curriculum (MoNE, 2013), the subject of fractions was taught for both grade students through four lessons per week for twelve weeks. In the designed learning environment, different methods (educational games, concrete materials, computer applications, and problem solving in cooperative heterogeneous groups - Figure 1-e, f) were used together. The study by Erdem (2015) was used to guide the development of the activities employed in these methods. In the following, one sample educational game and one computer application are explained in detail.

Game 1. Get Highest Score by Hitting Goal: This educational game is designed to help students reach the learning outcomes "compare and sort the fractions" and "make the operations of addition and subtraction with fractions." In this game, the students are required to shoot a dart with the expressions " $1, \frac{2}{3}, \frac{2}{4^{\prime}}, \frac{2}{5}, \frac{2}{6}, \frac{2}{7}, \frac{2}{8}$ " written from the inner circle to the outermost circle. It is advantageous for the students to compare these fractions and hit the region where the greatest fraction is. Students in each group will add up the fractions in the region where the shots hit after they have taken four shots. The group with the highest sum of incoming fractions will win the game and receive the prize. During the process, the students were asked questions such as "Which region should be hit? Why?", "Would it be advantageous if the blue region gets hit?", "What should we do to increase our chances of winning?", and "What is the purpose of this game?" to make them think critically and develop strategies for success. These questions were occasionally discussed and evaluated with the whole class. Images from the learning environment using this game are provided in Figure 1-c and d.

Application 1. Recognize, Model and Compare Fractions: This computer application is designed to help students reach the learning outcomes "compare and model the fractions" and "simplify and expand fractions." Through this application, students will learn to comprehend the meaning of the concept of fractions, as well as to model, simplify, expand, 
and compare fractions. In this application, when the corresponding model is selected correctly, the feedback "OK" is given; while "try again" is given when a false one is selected. In this way, students will have the opportunity to learn individually through the application's feedback. Also in this application the same fraction can be presented with different models such as area, length, and volume. Students also have the opportunity to learn how to model in fractions more regularly and in color. During the process, the students were asked questions such as "Can you show the same fraction with different models?", "What is the difference between these models?", "Why did you place the $\frac{36}{32}$ and $\frac{9}{8}$ fractions in the same space?", and "What is the purpose of this practice?" to ensure that they think critically and reflect on their learning. The visual aspects of the application and its playability attract students' attention. An image of this application is given in Figure 1-b.

Why fractions? The reasons for choosing this particular concept for the study include (a) the fact that fractions are among the subjects that students have the most difficulty in learning (see Behr, Lesh, Post \& Silver, 1983; Moss \& Case, 1999), (b) the "fractions" topic is a sub-learning area of the most comprehensive basic learning area of "numbers and operations" in the Turkish Middle School Mathematics Lesson (5th, 6th, 7th and 8th Grades) Curriculum (MoNE, 2013), and (c) the need for fractions in many areas of daily life. Some reflections from the application process are given in Figure 1. Throughout the entire implementation process, questions such as "Why do you think so?", "How did you reach this conclusion?", "Why?", "What else could it be?", and "What happens if that happens?" were asked to recognize and develop students' MR skills. In addition, in order to develop the students' MR in different ways, discussions were encouraged in collaborative groups in solving problems that required reasoning in fractions (See Figure 1-f).

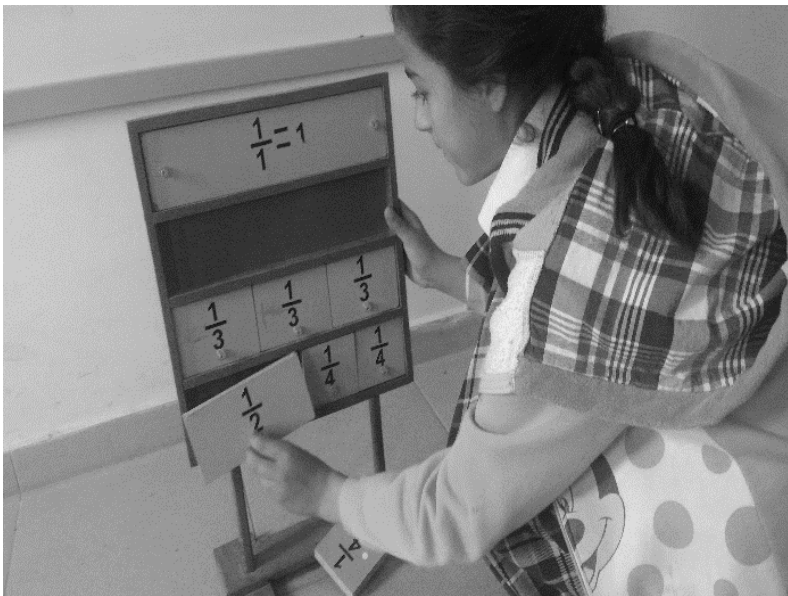

a.

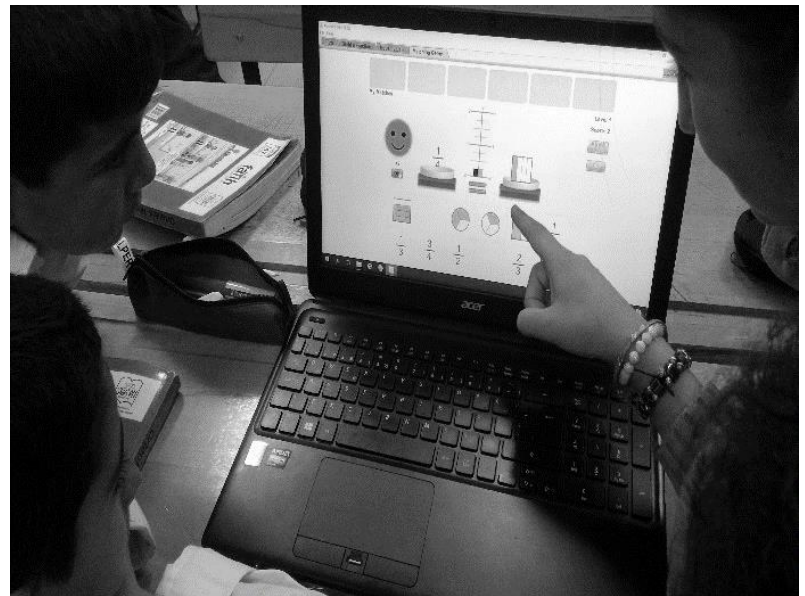

b. 


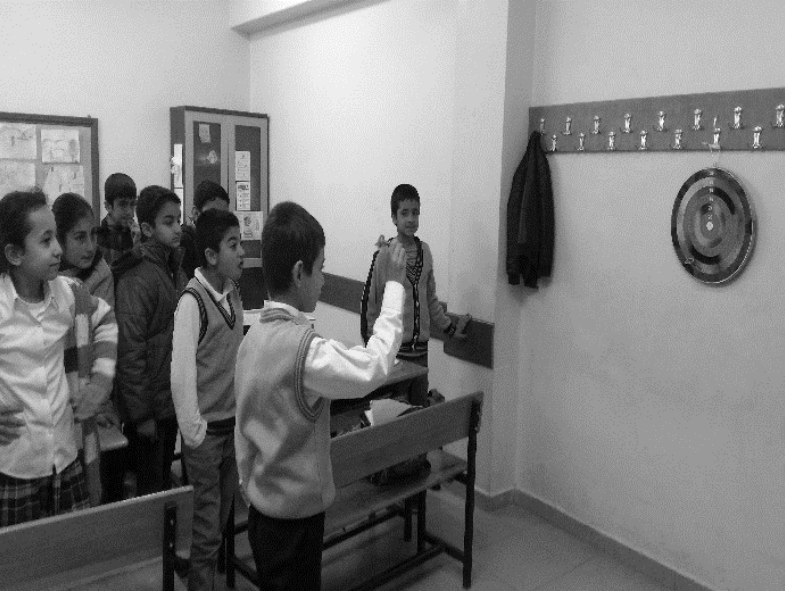

c.

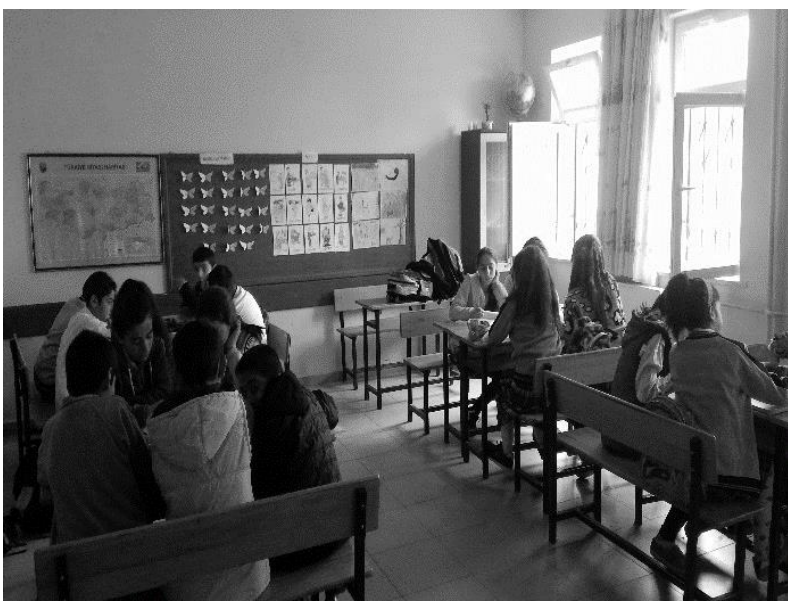

e.

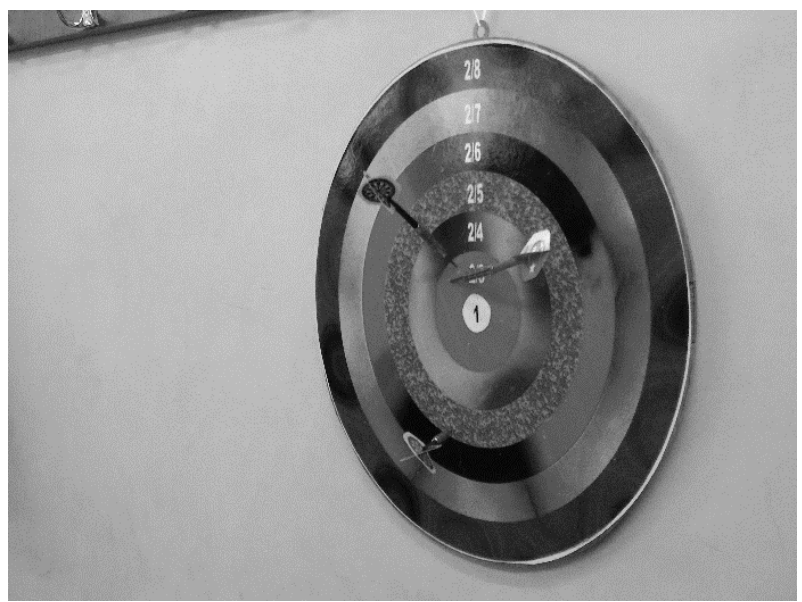

d.

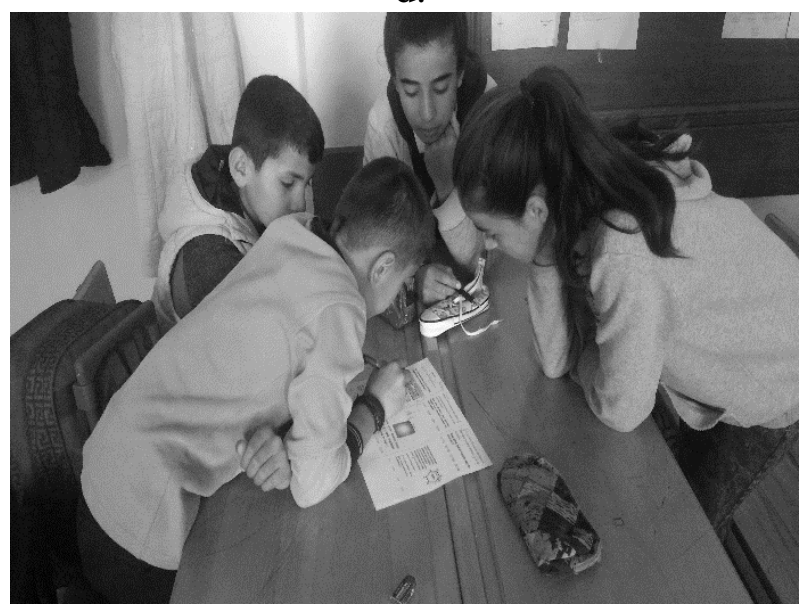

f.

Figure 1. Reflections from the learning environment

\section{Findings}

The effect of the designed environment on participants' MR and MA was statistically determined. Some of the process reflections and group argumentations are also provided here to give context for these statistics.

Table 3. Pre-test and post-test results of grade 5 students on MRT

\begin{tabular}{ccccccc}
\hline Scale & & $\mathbf{N}$ & $\overline{\mathbf{X}}$ & Sd & Z & p \\
\hline \multirow{2}{*}{ MRT } & Pre-test & 17 & 24,24 & 3,99 & & \\
& Post-test & 17 & 55,24 & 17,91 & & \multirow{2}{*}{000} \\
\hline
\end{tabular}

a. Based on positive ranks

As seen in Table 3, analysis shows that there is a significant difference between the pre-test and post-test scores of 5th grade students from MRT $(\mathrm{z}=3.625, \mathrm{p}<.05)$. The order averages and totals of the difference scores reveal that the observed difference is in favor of positive sequences - in other words, to the post-test. Based on this result, it can be said that 5th grade students' post-test scores were significantly higher than their pre-test scores. This finding showed that the MR of the 5th graders developed significantly. 
Table 4. Pre-test and post-test results of grade 6 students on MRT

\begin{tabular}{ccccccc}
\hline Scale & & $\mathbf{N}$ & $\overline{\mathbf{X}}$ & $\mathbf{S d}$ & $\mathbf{Z}$ & $\mathbf{p}$ \\
\hline \multirow{2}{*}{ MRT } & Pre-test & 18 & 32,50 & 16,71 & & \\
& Post-test & 18 & 65,61 & 14,33 & & \multirow{2}{*}{000} \\
\hline
\end{tabular}

a. Based on positive ranks

As shown in Table 4, there was a significant difference between the pre-test and posttest scores of the 6th grade students $(z=3.724, p<.05)$. The order averages and totals of the difference scores reveal that the observed difference is in favor of positive sequences-in other words, to the post-test. This result shows that the 6th grade students' post-test scores were significantly higher than their pre-test scores. Thus, the MR of the 6th graders improved significantly.

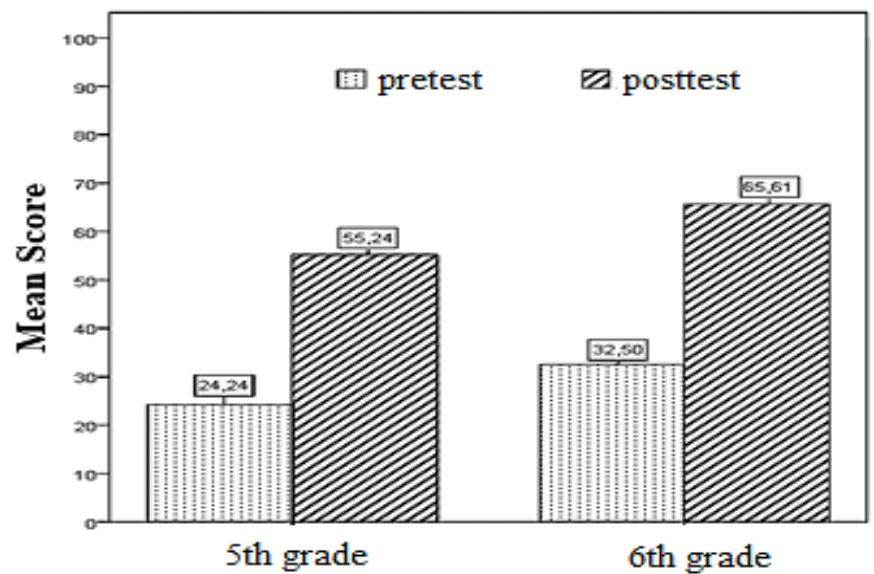

Chart 1. Change of both grade students' pre-and post-test results on MRT

As Chart 1 illustrates, the MR of both the 5th and 6th grade students developed significantly over the course of the study implementation. Both the pre-test and post-test averages of Grade 6 students are higher than the averages of Grade 5 students. It was also found that the age factor affected the scoring in both measurements.

Table 5. Pre-test/post-test score differences of groups on MRT

\begin{tabular}{cccccc}
\hline Scale & Grade & Posttest-Pretest & Sd & Z & p \\
\hline \multirow{2}{*}{ MRT } & 5 & 31,00 & 15,28 &, 545 &, 586 \\
& 6 & 33,11 & 15,19 & & \\
\hline
\end{tabular}

a. Based on positive ranks

The results in Table 5 show that the effect of grade was not significant in the development of the MR of 5 th and 6th grade students $(z=.545, p>.05)$. It was determined that the pre-test/post-test point differences between groups were not significant. In other words, the study found that grade/age did not make a significant difference in the development of 
MR. Some student answers to tasks on the MRT in each grade from the pre-test and post-test are given below and interpreted.

Task 11

When a farmer cultivates half of the farm wheat and half of the remaining barley, 15 decares remain empty. How many decares does this farmer have? Please explain.

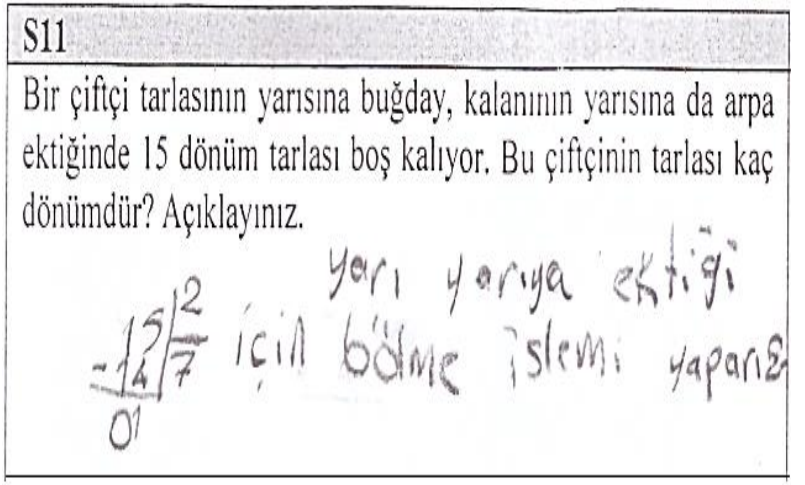

Answer in Pre-test

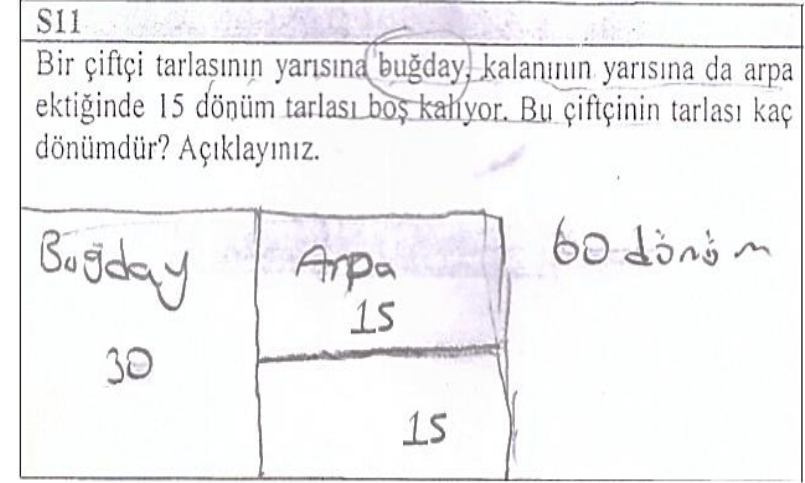

Answer in Post-test

Figure 2. Answers of Student E (Grade 5) in pre-test and post-test to the 11th task in the MRT In Figure 2, when Student E's answered the 11th task in the pre-test is, the student divided 15 by 2 as a solution to the problem and explained that "... we divide because it is cultivated for half...". In this solution, the student divides 15 by 2 by taking the expression "half" and the number "15" from the task sentence. The student had not developed any strategy to solve this task in the pre-test. From the solutions, it can be said that the MR of Student E on this task in the pre-test is not good. This is also confirmed by the average score from the MRT. The pre-test score of the student was calculated as 0.87 . This average falls within the "Quite Low" MR level range (0.00-0.99). Considering the answer of the same student in the post-test on this task, it can be said that he developed a strategy and displayed the expected reasoning. The student thought of the farm as a rectangular region and divided it into two pieces, half of which was wheat, and half of the remaining barley. He found that the farm was "60 decares" in total, indicating that the empty part was 15 decares, the barley planted part 15 decares, and the wheat planted part 30 decares on the visual. The post-test score of the student was calculated as 2.84 . This average falls within the "medium" MR level range (2.00-2.99). In the light of these test averages and evaluations, it can be said that the MR of the Student E has improved considerably as a result of the intervention. 
Task 10

Hasan Bey spent a quarter of his life as a child, one-third as a teenager, one-third as a middle-aged adult, and 5 years as an aged adult. According to this, how old was Hasan Bey when he died? Please explain.

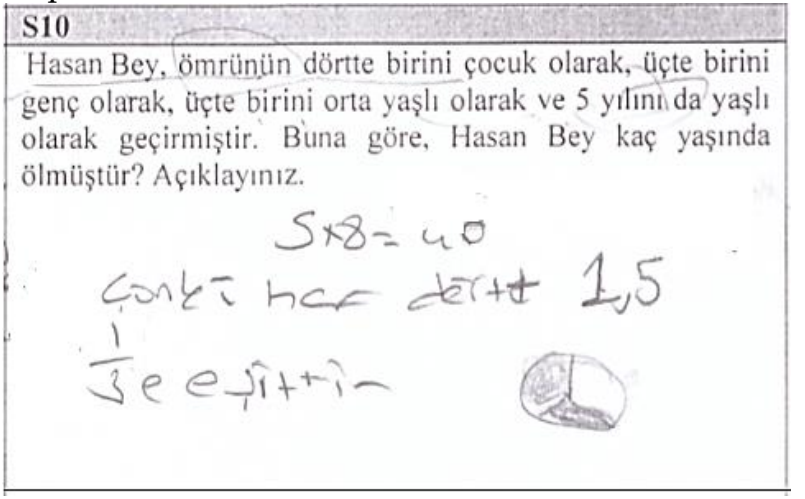

Answer in Pretest

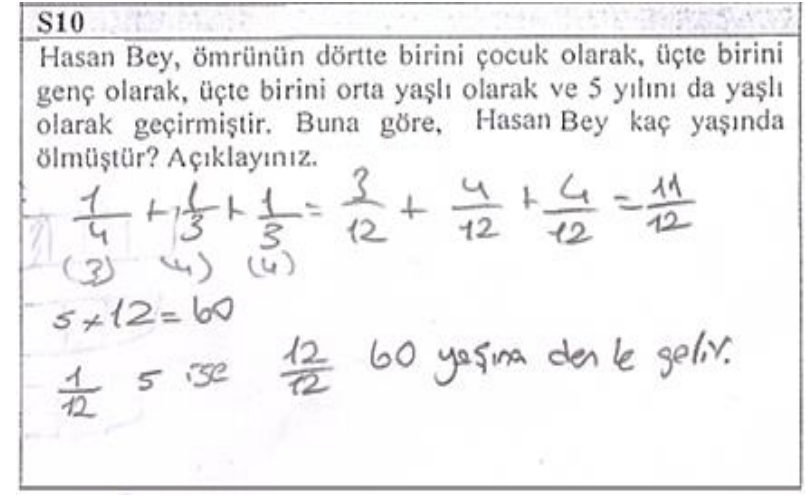

Answer in Posttest

Figure 3. Answers of Student F (Grade 6) in pre-test and post-test to the 10th task in the MRT

Figure 3, provides both the pre- and post-test answers of Student F to the 10th task in the MRT. In the pre-test, the student found the answer $5 \times 8=40$ and tried to visualize the total age by drawing a circle graph. On this circle graph, the student shaded two slices showing two periods in Mr. Hasan's lifetime. In an interview with Student F about the solution of this task, she used expressions that demonstrated limited certainty, such as "... I could do other questions, but in this...", "... Mr. Hasan spent one-third of his life as a teenager and one-third as middle-aged. So...", "I showed them on the circle but...". However, the student had a somewhat high score from the MRT. Student F's pre-test MR score was calculated as 3.15. This average falls within the "high" MR level range (3.00-3.99). When observing the same student's answer to this task in the post-test, she demonstrates the expected reasoning. The student determined the correct fractions indicating each phase of life and added them. She determined the whole life as $\frac{12}{12}$ and found that the remaining $\frac{1}{12}$ piece was equal to five years. Thanks to the correct reasoning and correct operations, Student F reached the correct result by explaining that "If $\frac{1}{12}$ piece is $5, \frac{12}{12} \mathrm{Mr}$. Hasan will be 60 years old". The post-test score of Student F was calculated as 4.66. This average falls within the "quite high" MR level range (4.00-5.00). Thus, it is reasonable to say that that the MR of Student F developed as a result of the study intervention as well.

When these solutions, explanations, and test averages are examined, it is evident that the MR of most of the students improved as a result of the intervention. However, the 
average MRT scores of some students did not change much at the end of the intervention (one student in grade 6 and two students in grade 5).

On the other hand, in order to better understand the effect of constructive argumentation on solving open-ended problems in cooperative groups, quotations related to one problem solved by a group of 6th grade students are given below.

Argumentation in a group of 6 th grade students

Problem 2 (“SBS"):
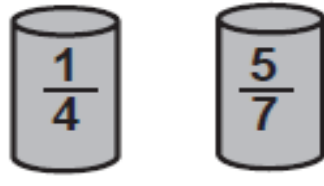

I

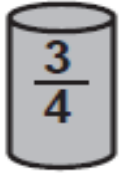

II

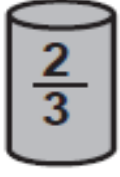

III

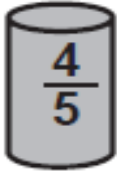

IV

The above glasses were filled with the amounts of water that is written on them. Which glass overflows when the left-most glass, one-fourth of which is filled with water, pours into it?

Student D: We multiply separately with each fraction (He looks at his friends and says without confidence).

Student Ç: No no... I think we sum them...

Researcher: So, how do we get it?

(Silence)

Student Ç: We need to equate the denominators.

(Other friends confirm without sure).

Researcher: Okay, let's do it.

(Student L is processing, while the researcher warns: Do you not need to equate the denominators?)

Student L: Teacher, I will do it myself.

(Then the other students in the group are also affected by the discourse of $\mathrm{L}$ and they tell the researcher that they will do it.)

Individual processing for a long time...

Researcher: Now 1/4 of the glass is full. Should we pour the water in this glass into glass I, which is filled with 5/7? Say what?

They continue to process...

Student D: I found the result 6/28. 
Researcher: How did you find this result?

Student D: I equated the denominators and sum the numerators.

Student Ç: False...

Student D: I forgot to expand the numerators.

Student D: Teacher, wait... (processing)

Student Ç: Then we equate the denominators. (Respectively) If we multiply this by 4, then we get 28

(The result found by equating the denominators)

(The others are listening Ç)

Student Ç: The result is 27/28. But the glass is not overflowing. We need to figure out which cup is overflowing.

Researcher: Well, let's try other glasses.

The students then state that the denominators should be equated again.

Researcher: What is the relationship between the numerator and the denominator for the overflow of the glass?

Student L: Is that a compound fraction?

Student Ç: If the numerator is equal to the denominator still does not overflow, it becomes full. So when the sum is done, the numerator must be bigger than the denominator... When we pour into the last glass, it becomes 21/20. That's why it's the glass IV.

The other students approve what they understand by nodding.

In the above group argumentations, students have contributed to each other spontaneously, without awareness. Students with low MR can see how they approach their problems from friends with high MR and develop strategies to improve their approach. It was observed that students with high MR contributed to the consolidation of their mathematics knowledge and skills because they made statements to their friends. It was also evident that, in addition to MR, the friends in the group also contributed to the development of language skills.

The effects of the intervention on students' MA, another main purpose of the study, is given in Table 6, Table 7, Table 8, and Chart 2.

Table 6. Pre-test and post-test results of grade 5 students on MAS

\begin{tabular}{ccccccc}
\hline Scale & & $\mathbf{N}$ & $\overline{\mathbf{X}}$ & Sd & $\mathbf{Z}$ & $\mathbf{p}$ \\
\hline \multirow{2}{*}{ MAS } & Pre-test & 17 & 77,71 & 11,37 & & \\
& Post-test & 17 & 81,94 & 9,76 & $1,636^{\mathrm{a}}$ &, 102 \\
\hline
\end{tabular}

a. Based on positive ranks 
Table 6 shows that there is no significant difference between the pre-test and post-test scores of Grade 5 students on MAS ( $\mathrm{z}=1.636, \mathrm{p}>.05)$. Based on this result, it can be said that there is an increase between pre-test and post-test in 5th grade students' MA, but this increase is not significant.

Table 7. Pre-test and post-test results of grade 6 students on MAS

\begin{tabular}{cllcccc}
\hline Scale & & $\mathbf{N}$ & $\overline{\mathbf{X}}$ & $\mathbf{S d}$ & $\mathbf{Z}$ & $\mathbf{p}$ \\
\hline \multirow{2}{*}{ MAS } & Pre-test & 18 & 82,50 & 12,98 & $1,242^{\mathrm{a}}$ & \multirow{2}{*}{214} \\
& Post-test & 18 & 87,78 & 14,17 & & \\
\hline
\end{tabular}

a. Based on positive ranks

Table 7 shows that there is no significant difference between the pre-test and post-test scores of the 6th grade students on MAS ( $z=1.242, p>.05)$. This result shows that there is an increase between pre-test and post-test in 6th grade students' MA but this increase is not significant. The change in the MAS at both grades can also be observed in Chart 2 .

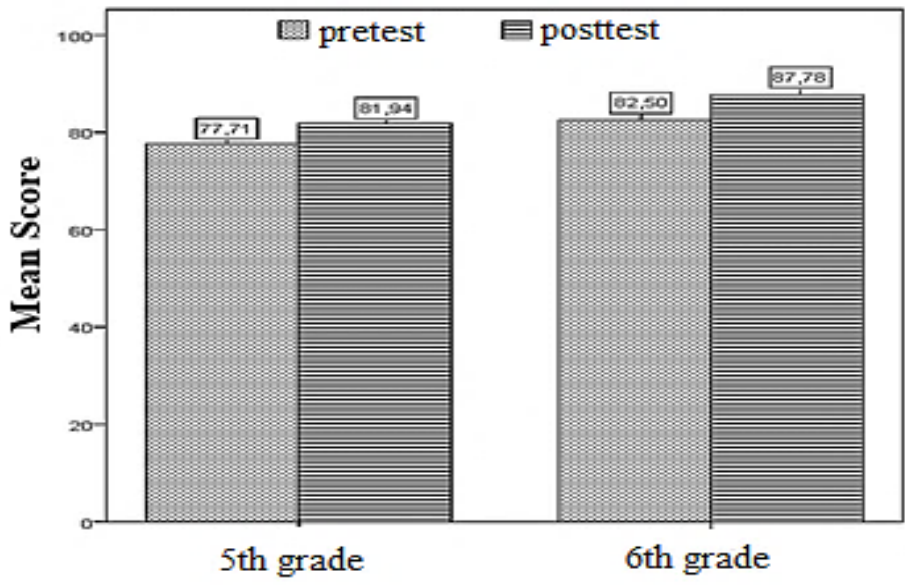

Chart 2. Change of both grade students' pre- and post-test results on MAS

Table 8. Pre-test/Post-test score differences of groups on MAS

\begin{tabular}{cccccc}
\hline Scale & Grade & Posttest-Pretest & Sd & Z & p \\
\hline \multirow{2}{*}{ MAS } & 5 & 4,24 & 9,41 &, 744 &, 457 \\
& 6 & 5,28 & 15,70 & & \\
\hline
\end{tabular}

a. Based on positive ranks

The results in Table 8 show that the effect of grade/age on the MA of both groups of students was not significant. $(\mathrm{z}=.744, \mathrm{p}>.05)$. In other words, it was found that there was no significant difference between the grades in terms of the effect of intervention on improvement of MA. 


\section{Discussion and Conclusions}

This study investigated the effects of a learning environment enriched by different teaching methods on the development of Mathematics Reasoning (MR) and Mathematics Attitude (MA) for 5th and 6th grade students in a middle school in a rural region. Based on the findings, the study has reached four conclusions. First, it was determined that the intervention in this environment significantly improved the MR of 5th and 6th grade students. The development of MR of all participants was determined by the MRT, which includes tasks about fractions and requires reasoning. Since the order of the learning environment and its activities are related to fractions, the MR of the participants has improved. Such an intervention over a long period of twelve weeks was also effective in the emergence of this development. On the other hand, the use of different teaching methods such as educational games, computer applications, and constructive argumentation in cooperative groups was another factor. NCTM (1989) also suggests to use group activities and technology to improve MR, as well as problem situations that interest students. This result of the present study supports the previous literature revealing that providing students with the opportunity to explain their thoughts about the reasoning of their friends (Erdem, 2015; Pape et al., 2003), organizing the class in cooperative groups (Erdem, 2015), using technology-supported applications (Kramarski \& Zeichner, 2001), teaching with educational games (Olson, 2007) are suitable grounds for the development of students' MR.

Second, the study found that the intervention did not make a significant difference between the grades in terms of the development of MR, contrary to studies (e.g. DeLay et al., 2015; Erdem \& Soylu, 2017) that show that MR develops with increasing age. The difference between the post-test scores of the 6th grade group and the pre-test from the MRT was 33.11, and the 5th grade group's difference was calculated as 31.00. Based on this result, it can be said that 6th grade students benefit slightly more from this changed learning environment. However, since these averages were close to each other, no statistically significant difference was observed. There is one year difference between the age of the students in these groups, and older children can be expected to show more development. The fact that the 5th grade group had not received formal training in fractions before could explain the emergence of this result. It is expected that there will be more development after training on a subject for learners that have no prior knowledge of that subject. As a matter of fact, the mean score of 
the 5th grade group was 24.24 in the pre-test and it increased to 55.24 in the post-test. The change in the 6th grade group was from 32.50 to 65.61 . The higher average score of the 6th graders in the pre-test may be explained by the fact that they have received previous training on fractions (when they were in the 5th grade one year ago). Another reason why there is no significant difference between the groups is the effect of primary school teachers. The groups were trained by different teachers in primary school for four years. It can be said that the knowledge and experience of the different teachers who educate these students has an effect on the emergence of this result. This inference is supported by studies that show that primary school teachers' knowledge directly affects students' mathematics achievement (e.g., Hill, Rowan \& Ball, 2005). It is also suggested that, when compared with the experiences of older students, elemantary school teachers affect the mathematics achievement of their students in primary school more easily (Hill et al., 2008).

Third, this study found that there was an improvement in the MA of the students at both grade levels, though this development was not statistically significant. Looking at the findings, the average of the pre-test attitude scores of both groups was high. The most important reason for the non-significant change in MA is likely the constructivist approach applied at all levels of education in Turkey in recent years. In the context of the constructivist approach, students are taught mathematics lessons in a student-centered way that is considered more fun and engaging than traditional approaches. The higher attitude of 6 th grade students recorded in the pre-test supports this conclusion. Grade 6 students received more than one year of mathematics education based on the constructivist approach than the grade 5 students. Therefore, the fact that participants have a high level of positive MA prior to intervention means that they have little to no prejudice against mathematics. A recent study found that students' math anxiety decreased at different levels (primary, middle, and high school) compared to the results of previous research (e.g. Erdem, 2017). Another reason for the high level of MA in the present study may be the simplification of the content of the mathematics courses following the arrangements in the curriculum. By simplifying the content of the mathematics courses, students can develop more positive attitudes when they realize that they can do mathematics. For example, the subject of probability, which is a subject which requires MR, started in the 4th grade (primary school) in the previous curriculum, but is now introduced for the first time in the 8th grade (middle school) in new curriculum (MoNE, 2013). 
Fourth, the study found that there was no significant difference between the groups in terms of effect of intervention on MA. The clearest reason for this result is that the same intervention program was implemented by the same researcher for both groups. It can also be said that the age difference between the groups is very low and that they receive education from the same mathematics teacher during their middle school education (5th, 6th, 7th, and 8th grades) - and both of these are factors that contribute to this result. The fact that there was no significant difference between the development of MR of the groups also supports this conclusion. In other words, there was no significant difference between the groups in terms of improvement of both MR and MA, since the groups were very close to each other in both age and past learning experience. It is also possible to approach this conclusion from a different perspective: grade 6 students' MA could be expected to improve significantly as a result of the intervention, because of the students' more advanced age and experience. However, the previous research shows that there is not always a direct correlation between grade/age and MA improvement. For example, several studies have actually demonstrated that mathematics anxiety increases as age increases (e.g., Baloğlu \& Koçak, 2006; Mutodi \& Ngirande, 2014; Randolph, 1997).

Additionally, the problems presented to students during the study were ones that they could not solve immediately without their pre-existing knowledge, thus requiring the students to develop strategy and MR. It was observed that solving these problems in cooperative groups contributed to the development of students' MR. This result confirms the claim that Lithner (2000b) made about the argumentation-reasoning relationship, explaining that "Argumentation is the substantiation, the part of the reasoning that aims at convincing oneself, or someone else, that the reasoning is appropriate" (p. 166). This experience provided students with the opportunity to discuss these problems with their friends to reach a solution, reinforcing their friendship, developing a mathematics language without being aware of it, and correcting each other's misconceptions. Allowing the students to deal with increasingly difficult problems each week also differentiated their ways of thinking after a while, leading them to multidimensional thinking and thus contributing to the development of their reasoning. This result confirms the previous studies (Erdem, 2015; Kuhn et al., 1997; Yackel et al., 1999) by showing that learning by discussion contributes to the development of MR skill. 
Furthermore, the students stated that they used the rules directly in the mathematics lessons that they experienced before, and that they also memorized many formulas. It can be said that such a mathematics education will lead to superficial learning and thus the information learned without querying will not be permanent. From the beginning of the training given in the present research, students were encouraged to understand the underlying logic of rules instead of memorizing them. Thus, we can assert that the students who learn how the rules work have developed their query skills, and that this positively affects their reasoning. In the middle of the training process, the students examined the rules by asking questions like "Why are we equating the denominators of fractions?", and "Why is $\frac{2}{3}$ greater than $\frac{2}{7}$ ?". This result supports Norqvist (2018)'s research, which asserts the importance of questioning the rules to MR learning.

The MRT pre-test average of the 5th grade group was calculated as 24.24 , while the MRT pre-test average of the 6th grade group was 32.50. Based on the pre-test results, it can be said that the quality of the education in disadvantaged rural schools is reflected in the MR of these children. It can be said that children with low MR demonstrate similar levels of mathematical performance. This result supports the results of studies showing that disadvantaged students living in rural regions have difficulty in learning mathematics (Williams, 2005). This result can be explained by reasons such as the inability of parents to provide the necessary educational support to their children due to their low education level, the lack of necessary equipment, the low number of qualified teachers, and the low level of student motivation. In addition, these students' difficulties in mathematics will adversely affect their later learning. The literature illustrates that such failures in mathematics continue in the future (e.g., Jimerson et al., 1999). This undesirable situation will be have a critical impact on these children's career choices and lifestyles - in a sense, they will lead a similar life as their parents. Therefore, in order to prevent such children from having difficulty in mathematics in the future, there is a need for effective learning environments from early ages, as well as for teachers who will employ many different teaching methods in these environments. In summary, a devoted teacher who gives education to disadvantaged children in learning environments enriched by different teaching methods has the potential to raise them as individuals who have strong $\mathrm{MR}$ and therefore can do mathematics effectively. 
Acknowledgement

This study was funded by Adlyaman University Scientific Research Project Department (Proj. No: EFMAP/2017-0001)

\section{References}

Baloğlu, M., \& Koçak, R. (2006). A multivariate investigation of the differences in mathematics anxiety. Personality and Individual Differences, 40(7), 1325-1335.

Behr, M. J., Lesh, R., Post, T., \& Silver, E. A. (1983). Rational number concepts. In R. Lesh, \& M. Landau (Eds.), Acquisitions of mathematics concepts and processes (pp. 92-126). New York: Academic Press.

Bragg, L. A., Herbert, S., Loong, E. Y. K., Vale, C., \& Widjaja, W. (2016). Primary teachers notice the impact of language on children's mathematical reasoning. Mathematics Education Research Journal, 28(4), 523-544.

Brodie, K. (2010). Teaching mathematical reasoning in secondary school classrooms. New York: Springer.

Clarkson, P. C. (2004). Researching the language for rational explanations in mathematics teaching and learning. In Australian Association for Research in Education Conference, Melbourne, Australia.

Çiftçi, Ş. K., \& Cin, F. M. (2018). What matters for rural teachers and communities? Educational challenges in rural Turkey. Compare: A Journal of Comparative and International Education, 48(5), 686-701.

DeLay, D., Laursen, B., Kiuru, N., Poikkeus, A. M., Aunola, K., \& Nurmi, J. E. (2015). Stable same-sex friendships with higher achieving partners promote mathematical reasoning in lower achieving primary school children. British Journal of Developmental Psychology, 33(4), 519-532.

Ellis, A., Özgür, Z., \& Reiten, L. (2018). Teacher moves for supporting student reasoning. Mathematics Education Research Journal, https://doi.org/10.1007/s13394-018-0246-6

Erdem, E. (2011). An investigation of the seventh grade students' mathematical and probabilistic reasoning skills (MA Thesis). Adiyaman University, Turkey

Erdem, E. (2015). The effect of enriched learning environment on mathematical reasoning and attitude (Doctoral dissertation). Ataturk University, Turkey.

Erdem, E. (2017). A current study on grade/age-and gender-related change in math anxiety. European Journal of Education Studies, 3(6), 396-413.

Erdem, E., \& Soylu, Y. (2017). Age-and gender-related change in mathematical reasoning ability and some educational suggestions. Journal of Education and Practice, 8(7), 116127.

Erdem, E., \& Soylu, Y. (2019). The effect of a learning environment designed using different teaching ways on mathematical reasoning and mathematics attitude. Kastamonu Education Journal, 27(3), 1273-1290. 
Fan, X., \& Chen, M. (1999). Academic achievement of rural school students: A multi-year comparison with their peers in suburban and urban schools. Journal of Research in Rural Education, 15, 31-46.

Gersten, R., \& Chard, D. (1999). Number sense: Rethinking arithmetic instruction for students with mathematical disabilities. The Journal of Special Education, 33(1), 18-28.

Hill, H. C., Rowan, B., \& Ball, D. L. (2005). Effects of teachers' mathematical knowledge for teaching on student achievement. American Educational Research Journal, 42(2), 371-406.

Hill, H. C., Blunk, M. L., Charalambous, C. Y., Lewis, J. M., Phelps, G. C., Sleep, L., \& Ball, D. L. (2008). Mathematical knowledge for teaching and the mathematical quality of instruction: An exploratory study. Cognition and instruction, 26(4), 430-511.

Holyoak, K. J. \& Morrison, R. G. (2005). Thinking and reasoning: A reader's guide. In K. J. Holyoak \& R. G. Morrison (Eds.), The Cambridge handbook of thinking and reasoning (pp. 1-9). New York, NY: Cambridge University Press.

Hunter, R. (2008). Facilitating communities of mathematical inquiry. In M. Goos, R. Brown, \& K. Makar (Eds.). Navigating currents and charting directions (Proceedings of the 31st annual conference of the Mathematics Education Research Group of Australasia, Vol. 1, pp. 31-39). Brisbane: MERGA.

Hunter, R. (2012). Coming to 'know' mathematics through being scaffolded to 'talk and do' mathematics. International Journal for Mathematics Teaching and Learning. Retrieved from http://www.cimt.org.uk/journal/hunter2.pdf

Hunter, J. (2014). Developing learning environments which support early algebraic reasoning: A case from a New Zealand primary classroom. Mathematics Education Research Journal, 26(4), 659-682.

Jeannotte, D., \& Kieran, C. (2017). A conceptual model of mathematical reasoning for school mathematics. Educational Studies in Mathematics, 96(1), 1-16.

Jimerson, S., Egeland, B., \& Teo, A. (1999). A longitudinal study of achievement trajectories: Factors associated with change. Journal of Educational Psychoogy, 91(1), 116-126.

Judge, S., \& Watson, S. M. (2011). Longitudinal outcomes for mathematics achievement for students with learning disabilities. The Journal of Educational Research, 104(3), 147-157.

Kramarski, B. \& Zeichner, O. (2001). Using technology to enhance mathematical reasoning: Effects of feedback and self-regulation learning. Educational Media International, 38(23), 77-82.

Kuhn, D., Shaw, V., \& Felton, M. (1997). Effects of dyadic interaction on argumentative reasoning. Cognition and Instruction, 15, 287-315.

Lithner, J. (2000a). Mathematical reasoning and familiar procedures. International Journal of Mathematical Education in Science and Technology, 31(1), 83-95.

Lithner, J. (2000b). Mathematical reasoning in task solving. Educational Studies in Mathematics, 41, 165-190.

Lithner, J. (2003). Students' mathematical reasoning in university textbook exercises. Educational Studies in Mathematics, 52, 29-55. 
Lithner, J. (2017). Principles for designing mathematical tasks that enhance imitative and creative reasoning. ZDM, 49(6), 937-949.

Mason, J. (2001). Questions about mathematical reasoning and proof in schools. Opening address to QCA Conference, UK.

McCrone, S. (2005). The development of mathematical discussions: an investigation of a fifthgrade classroom. Mathematical Thinking and Learning, 7(2), 111-133.

Moss, J. \& Case, R. (1999). Developing children's understanding of the rational numbers: a new model and experimental curriculum. Journal for Research in Mathematics Education, 30(2), 122 - 147.

Ministry of National Education [MoNE]. (2013). Middle school mathematics 5-8. Classes teaching program. Ankara: Head Council of Education and Morality.

Mutodi, P., \& Ngirande, H. (2014). Exploring mathematics anxiety: mathematics students' experiences. Mediterranean Journal of Social Sciences, 5(1), 283-294.

National Council of Teachers of Mathematics [NCTM]. (1989). Curriculum and evaluation standards for school mathematics. Reston, Virginia.

Nisbet, S. (2006). Mathematics without attitude. Keynote address to the Annual Conference of the Queensland Association of Mathematics Teachers, Brisbane.

Norqvist, M. (2018). The effect of explanations on mathematical reasoning tasks. International Journal of Mathematical Education in Science and Technology, 49(1), 15-30.

Olson, J. (2007). Developing students' mathematical reasoning through games. Teaching Children Mathematics, 13(9), 464-471.

Öğdül, H. G. (2010). Urban and rural definitions in regional context: A case study on Turkey. European Planning Studies, 18(9), 1519-1541.

Pape, S. J., Bell. C. V., \& Yetkin, I. E. (2003). Developing mathematical thinking and selfregulated learning: A teaching experiment in a seventh-grade mathematics classroom. Educational Studies in Mathematics 53, 179-202.

Randolph, T. D. (1997). An assessment of mathematics anxiety in students from grades four through eight. Unpublished doctoral dissertation, Southern Illinois University at Carbondale, United States-Illinois.

Schliemann, A. D. \& Carraher, D. W. (2002). The evolution of mathematical reasoning: Everyday versus idealized understandings. Developmental Review, 22(2), 242-266.

Staples, M. E., \& Truxaw, M. P. (2012). An initial framework for the language of higher-order thinking mathematics practices. Mathematics Education Research Journal, 24(3), 257-281.

Starkey, P., Klein, A., \& Wakeley, A. (2004). Enhancing young children's mathematical knowledge through a pre-kindergarten mathematics intervention. Early Childhood Research Quarterly, 19(1), 99-120.

Şengül, S. \& Dereli, M. (2013). The effect of learning integers using cartoons on 7 th grade students' attitude to mathematics. Educational Sciences: Theory E Practice, 13(4), 25092534.

Uğurel, I. \& Moralı, S. (2006). Cartoons and their use in mathematics. National Education, 170, 32-47. 
Vygotsky, L. S. (1978). Mind and society: The development of higher mental processes. Cambridge, MA: Harvard University Press.

Williams, J. H. (2005). Cross-national variations in rural mathematics achievement. Journal of Research in Rural Education, 20(5), 20-5.

Yackel, E. Cobb, P., \& Wood, T. (1999). The interactive constitution of mathematical meaning in one second grade classroom: An illustrative example. Journal of Mathematical Behavior, 17(4), 469-488.

Yackel, E. \& Hanna, G. (2003). Reasoning and proof. In J. Kilpatrick, G. Martin and D. Schifter (Eds.), A research companion to principles and standards for school mathematics (pp. 227-236). Reston, VA: National Council of Teachers of Mathematics.

Yankelewitz, D., Mueller, M., \& Maher, C. A. (2010). A task that elicits reasoning: A dual analysis. The Journal of Mathematical Behavior, 29, 76-85. 